\title{
Chemical Characteristics of the Karmanasha River Water and Its Appropriateness for Irrigational Usage
}

\author{
Anueva Acharya ${ }^{1}$, Motee Lal Sharma ${ }^{2}$, Kiran Bishwakarma ${ }^{3}$, Pragati Dahal', Satyam Kumar \\ Chaudhari $^{1}$, Barsha Adhikari', Shristi Neupane', Badri Nath Pokhrel', Ramesh Raj Pant*1 \\ ${ }^{I}$ Central Department of Environmental Science, Institute of Science and Technology, Tribhuvan University, Nepal \\ ${ }^{2}$ Central Department of Chemistry, Institute of Science and Technology, Tribhuvan University, Kathmandu, Nepal \\ ${ }^{3}$ Institute of Tibetan Plateau Research, Chinese Academy of Sciences, Beijing, China \\ *Corresponding E-mail: rpant@cdes.edu.np \\ (Received: April 5, 2020; Revised: June 18, 2020 \& Accepted: June 28, 2020)
}

\begin{abstract}
Water is a prime natural resource and precious national asset and one of the chief constituents of the environment. The chemical characteristics play a key role in terms of ecological and economic perspectives in the river water. The characterization and evaluation of river water quality in the Karmanasha River is necessary due to its immense importance in the livelihood of the people in the core urban areas of Kathmandu valley, Nepal. In this study, the surface water samples were collected from 16 sites with a $0.5 \mathrm{~km}$ interval to characterize and evaluate the water quality mainly from the perspective of its irrigational usage. The assessment was carried out by applying electrical conductivity (EC), sodium percentage $(\mathrm{Na} \%)$, sodium adsorption ratio (SAR), permeability index (PI), Kelly's ratio (KR), magnesium adsorption ratio (MAR), cation ratio of soil structural stability (CROSS), Wilcox diagram and water quality index (WQI) including the general hydrochemistry. The general hydrochemistry of river water indicates slightly alkaline in nature with mean $\mathrm{pH}$ value 8.07 , and the dominance order of major ions follows the pattern of $\mathrm{Ca}^{2+}>\mathrm{Mg}^{2+}>\mathrm{Na}^{+}>\mathrm{K}^{+}$for cations, and $\mathrm{HCO}_{3}>\mathrm{Cl}^{-}>\mathrm{NO}_{3}^{-}$ for anions. Furthermore, the results revealed that the water is safe for irrigation purposes based on $\mathrm{EC}, \mathrm{Na} \%$, SAR, KR, MAR, CROSS, and Wilcox diagram. The results also specified that no severe degradation in water, however, the low DO, and high BOD and COD values than that of the standard value prescribed by Nepal Drinking Water Quality Standard, signify the anthropogenic signature in the river water. This study provides the baseline information about the WQI and suitability of irrigation water quality, and further in-depth studies are required at spatiotemporal levels to get in-depth insights about the ecological health of the river.
\end{abstract}

Keywords: Spatial characterization, major ions, irrigation suitability, water quality index, Karmanasha River

\section{Introduction}

Water is one of the most essential for all living creatures for their survival, growth and development. The rapid degradation of water quality mostly in developing countries is due to various natural and anthropogenic activities [1] that can be measured as the loss of natural ecosystem and has direct impacts on the human and ecological health [2]. Moreover, the hydrochemical characteristics and water quality is primarily controlled by atmospheric precipitation, chemical weathering and evapo-crystallization processes [3,4]. Precisely, rapid urbanization, industrialization and other anthropogenic activities greatly responsible for the loss of water quality [3, 4]. The dissolved ions originated from the different natural and anthropogenic sources including calcium $\left(\mathrm{Ca}^{2+}\right)$, magnesium $\left(\mathrm{Mg}^{2+}\right)$, sodium $\left(\mathrm{Na}^{+}\right)$, potassium $\left(\mathrm{K}^{+}\right)$, bicarbonate $\left(\mathrm{HCO}_{3}^{-}\right)$, chloride $\left(\mathrm{Cl}^{-}\right)$, nitrate $\left(\mathrm{NO}_{3}^{-}\right)$, etc. have a significant role in defining the water quality $[5,6]$. Thus, the chemical characteristics of the river basin reflect by both the natural and anthropogenic interferences. For instance, the primary source of riverine $\mathrm{Ca}^{2+}, \mathrm{Mg}^{2+}$, and $\mathrm{HCO}_{3}{ }^{-}$are natural origin, whereas $\mathrm{NH}_{4}^{+}, \mathrm{NO}_{3}^{-}$, and $\mathrm{SO}_{4}^{2-}$ are 
influenced by anthropogenic activities [6,7]. These chemical parameters have a direct role in determining the drinking and irrigation water quality, and the hydrochemical characteristics in the riverwater have a key role in ecological sustainability and economic prosperity.

The Himalayan River water is widely used for irrigation, drinking, and other domestic purposes in Nepal. Although, Nepal is endowed with abundant freshwater water estimated to be about 225 billion $\mathrm{m}^{3}$ per annum, agricultural activities have suffered a serious setback because of climatic variability as well as uneven distribution of the resources including the impacts of various anthropogenic activities [4, 8]. Crop productivity is directly associated with the amount and quality of water, especially within the permissible limit of chemical constituents, used in the irrigation field. For instance, the average production of wheat, rice and corn decreased by $24 \%, 39 \%$ and $21 \%$, respectively in a normal yield with consumption of low-quality irrigation water [9]. The demand of water is in a increasing trend in agriculture and other sectors but the stress imposed due to urbanization, industrialization, poor land management, and environmental pollution that impacting its quality [10].

The overall concentration and dissolved ions in river water determine its suitability of irrigation purposes [11]. Numbers of literature available on river water qualities for irrigation and drinking purposes focusing on major ions and potentially toxic trace elements [4,12-16]. These scientific literatures have rightly suggested the suitability of freshwater for the drinking and irrigation purposes. However, there are minimal number of studies in the urban based small rivers, where the water is intensively used for irrigation and other domestic purposes $[14,15]$. Therefore, this study aims to assess the spatial characteristics and irrigation suitability of water quality in the Karmanasha River based on various geochemical indices and water quality index.

\section{Materials and Methods}

\section{Study area}

The Karmanasha (destroyer of the religious merit) River, is one of the most uncommon rivers flowing $\sim 12 \mathrm{~km}$ south to north, is located in the southern part of Kathmandu valley in Lalitpur District, Nepal. This is spring fed- river, which have high flow in the rainy season from June to September. The river extends from $27^{\circ} 35^{\prime} 17^{\prime \prime} \mathrm{N}$ to $27^{\circ} 65^{\prime} 65^{\prime \prime} \mathrm{N}$ and $85^{\circ} 20^{\prime} 36^{\prime \prime} \mathrm{E}$ to $85^{\circ} 33^{\prime} 86^{\prime \prime} \mathrm{E}$ (Fig. 1). The land use pattern of the catchment area is $10 \%, 60 \%, 20 \%$ and $10 \%$ of the forest, agriculture land, brick kilns and industries, respectively. All the rivers within the Kathmandu valley drain out to the Bagmati river, and prior to that this Karmanasha river first connects with the Manohara river.

\section{Sample collection and laboratory analysis}

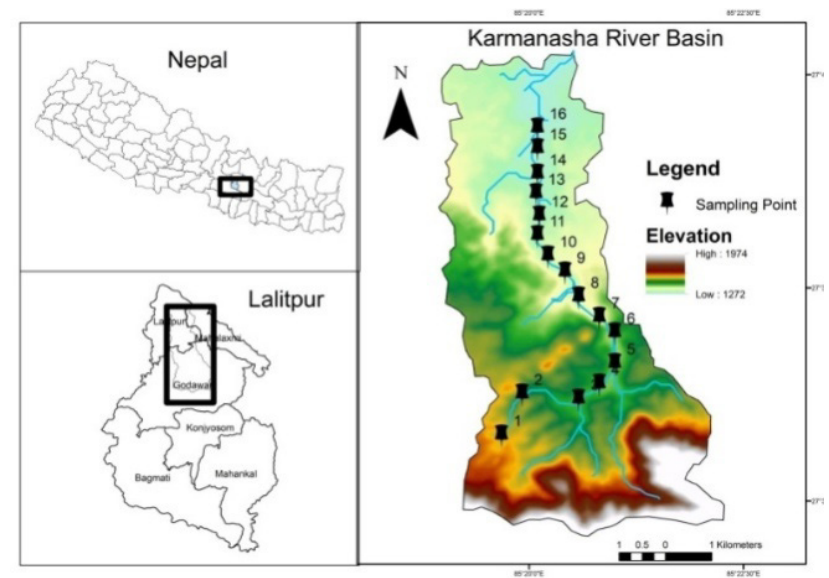

Figure 1: Map showing study area and sample locations of the Karmanasha River, Lalitpur, Nepal

The water samples were collected during winter season in December, 2019. A total of 16 water samples were collected with an interval of $0.5 \mathrm{~km}$ distance to get the proper insights about the contaminations in the river water. The hydro chemical properties of the river stream varies on the river channel geology as well as the anthropogenic contribution. Thus, the sampling site selection criteria include natural conditions, industrial effluent, land use change as well as pattern of anthropogenic activities. Each sample were collected in $1 \mathrm{~L}$ sampling bottle that was previously cleaned with metal free soap, repeatedly rinsed with distilled water, soaked in 10\% nitric acid for 24 hours. While transporting from the field to laboratory, all the samples maintained at $4^{\circ} \mathrm{C}$ in icebox.

The parameters were expressed in the units as water temperature:, EC: $\mu \mathrm{S} / \mathrm{cm}$ and all other parameters are in $\mathrm{mg} / \mathrm{L}$ except $\mathrm{pH}$. The physicochemical parameters such as temperature, $\mathrm{pH}, \mathrm{EC}$, TDS, dissolved oxygen (DO) were measured on-site using 
the multi-parameter instrument HANNA and DO by DO meter, while potassium $\left(\mathrm{K}^{+}\right)$, sodium $\left(\mathrm{Na}^{+}\right)$, calcium $\left(\mathrm{Ca}^{2+}\right)$, magnesium $\left(\mathrm{Mg}^{2+}\right)$, nitrate $\left(\mathrm{NO}_{3}^{-}\right)$, chloride $\left(\mathrm{Cl}^{-}\right)$, chemical oxygen demand (COD), and biological oxygen demand (BOD), and bicarbonate $\left(\mathrm{HCO}_{3}^{-}\right)$, were analyzed in the Central Department of Environmental Science, Tribhuvan University laboratory following the standard method $[4,16,17]$.

\section{Irrigation suitability assessment}

The chemical and physical characteristics of river water are the fundamental consideration for the irrigation water quality evaluation. Specific properties of irrigation water have relevant relation to the quantity and quality of crops, maintenance of soil properties and environment balance [18]. The specific physicochemical parameters are taken for the scientific irrigation water quality analysis such as: $\mathrm{EC}, \mathrm{HCO}_{3}{ }^{-}$, $\mathrm{Ca}^{2+}, \mathrm{Mg}^{2+}, \mathrm{Na}^{+}$, and $\mathrm{K}^{+}$. Many researchers purposed the different guidelines for irrigation water evaluation. The irrigation water quality of different sections in the Karmanasha River has been studied individually with the following parameters.

\section{Electrical conductivity}

Electrical conductivity (EC) qualitatively reflects the status of inorganic pollution and is a measure of total dissolved solids and ionized species in the waters [19]. Principally the EC is a measurement of ionic strength and it depends on the presence of ions, its concentrations, mobility and temperature. Other several factors determine the EC in freshwater environments such as temperature, ionic strength etc. It is used for the indication of the salinity hazard, which is the most significant water quality guideline on crop production [11]. High salinity in water is toxic for the plants that leads to salinity hazards [20]. The EC value $>3000$ is termed 'Fair' and seriously affect crop productivity. EC value $700-3000$ is defined as 'Good' and $<700$ refers to 'Excellent' water quality for irrigation purposes and crop production [21].

\section{Sodium percentage $(\mathrm{Na} \%)$}

It is one of the widely used parameters for the suitability assessment of irrigation water. Irrigation water with more than $60 \%$ sodium content may lead to breakdown in the soil's physical properties and excess Na-combining with carbonate may result in the formation of alkali soils [20]. The irrigation water quality can be classified into five major divisions based on $\mathrm{Na} \%$ values (excellent $<20$, good: $20-40$, permissible: 40-60, doubtful: $60-80$ and unsuitable $>80)[22,23]$ proposed the following relation to calculate $\mathrm{Na} \%$.

$$
\mathrm{Na} \%=\frac{\mathrm{Na}^{+}+\mathrm{K}^{+}}{\mathrm{Na}^{+}+\mathrm{Ca}^{2+}+\mathrm{Mg}^{2+}+\mathrm{K}^{+}} \times 100
$$

\section{Sodium adsorption ratio (SAR)}

It is a useful indicator of measurement of cation exchange reactions in the soil [4,22]. A continue use of water with a higher value of SAR may affect the soil and lead to breakdown its physical structure [24]. Irrigation water can be categorized in different four classes based on SAR values as excellent $<10$, good: $10-18$, fair: $18-26$, and poor: $>26$. The SAR is calculated as [25].

$$
\mathrm{SAR}=\frac{\mathrm{Na}^{+}}{\sqrt{\left\{\left(\mathrm{Ca}^{2+}+\mathrm{Mg}^{2+}\right) / 2\right\}}}
$$

\section{Magnesium adsorption ratio (MAR)}

The status of magnesium and calcium should always be in equilibrium for the suitability of irrigation purpose. Higher amount of magnesium in water makes it more alkaline, which has an adverse impact on crop yields [22]. A high concentration of $\mathrm{Ca}^{2+}$ and $\mathrm{Mg}^{2+}$ ions in irrigation water can increase soil $\mathrm{pH}$, resulting in reducing the availability of phosphorous [26]. MAR value $<50$ defines as suitable for irrigation purpose and $>50$ is unsuitable. Proposed the relation [28] to calculate MAR as follow.

$$
\mathrm{MAR}=\frac{\mathrm{Mg}^{2+}}{\mathrm{Ca}^{2+}+\mathrm{Mg}^{2+}} \times 100
$$

\section{Kelly's ratio (KR)}

Kelly's ratio is an important parameter used in the evaluation of water quality for irrigation [27]. Suitability of KR evaluation method is based on $\mathrm{Na}^{+}$, $\mathrm{Ca}^{2+}$ and $\mathrm{Mg}^{2+}$ contents in irrigation water. According to $\mathrm{KR}$ value, $<1$ is safe for irrigation and $>1$ is unsafe. KR value is calculated by using the following relation.

$$
\mathrm{KR}=\frac{\mathrm{Na}^{+}}{\mathrm{Ca}^{2+}+\mathrm{Mg}^{2+}}
$$




\section{Permeability index (PI)}

Long term use of irrigation water affects the permeability of soil [22]. The classification of water for irrigation based on the PI is based on $\mathrm{Na}^{+}, \mathrm{Ca}^{2+}$, $\mathrm{Mg}^{2+}$, and $\mathrm{HCO}_{3}^{-}$which have long term effect on soil properties [22]. PI values can be classified into three major classes ( $>75$ : class I, 25-75: class II and $<25$ : class III). PI values can be calculated by using the following formula 5 .

$$
\mathrm{PI}=\frac{\mathrm{Na}^{+}+\sqrt{\mathrm{HCO}_{3}}{ }^{-}}{\mathrm{Na}^{+}+\mathrm{Ca}^{2+}+\mathrm{Mg}^{2+}} \times 100
$$

\section{Cation ratio of soil structural stability (CROSS)}

It is used as an appropriate parameter to determine the relation to soil structural stability [28]. This method is also analogous to SAR irrigation water and can be categorized in different four classes based on CROSS values (excellent $<10$, good: $10-18$, permissible: 18 26 , and unsuitable : $>26$ ) and calculated by formula 6 .

$$
\text { CROSS }=\frac{\mathrm{Na}^{+}+0.56 \mathrm{~K}^{+}}{\sqrt{\left\{\left(\mathrm{Ca}^{2+}+0.6 \mathrm{Mg}^{2+}\right) / 2\right\}}}
$$

\section{Wilcox diagram}

Wilcox diagram is also known as US Salinity diagrams [29] is commonly used for the evaluation of irrigation water quality [30]. In the Wilcox diagram, for irrigation, water with low-salinity $(\mathrm{C} 1)$ indicates most appropriate, medium-salinity water $(\mathrm{C} 2)$ reveals permissible, high salinity water (C3) indicates poor quality and very high salinity water (C4) is highly unsafe. The classification of irrigation water with respect to sodium hazard is primarily based on the effect of exchangeable sodium on the physical condition of the soil. According to classification of sodium hazard, low sodium water (S1) indicates suitability in almost soil, medium-sodium water (S2) is appreciable, high-sodium water (S3) may be harmful and very high sodium water (S4) generally unsafe for irrigation purpose.

\section{Water quality index (WQI)}

WQI is the useful tool that represents the overall water quality at a specific place and time based on physicochemical parameters [31].WQI can be calculated using the equation (7).

$$
\mathrm{WQI}=\frac{\sum \mathrm{qnW}}{\sum \mathrm{Wn}}
$$

Where, $q n$ and $W n$ be the quality rating and unit weight of $n^{\text {th }}$ water quality parameter. The quality rating $(q n)$ is calculated using the relation given in equation (8).

$$
\mathrm{Qn}=\left[\frac{\mathrm{Vn}-\text { Vio }}{\mathrm{Sn}-\text { Vio }}\right] \times 100
$$

Where, $V n$, and $S n$ be the estimated value, ideal value and standard permissible value of the $\mathrm{n}^{\text {th }}$ parameter. For all parameters, ideal values (Vio) were taken as zero for drinking water except for $\mathrm{pH}=7.0$ and $\mathrm{DO}=$ $14.6 \mathrm{mg} / \mathrm{L}$. The unit weight $(W n)$ is calculated using equation (9).

$$
\mathrm{Wn}=\frac{\mathrm{K}}{\mathrm{Sn}}
$$

Where, $K=$ proportional constant and it is calculated by using the relation given in equation (10).

$$
\mathrm{K}=\frac{1}{\sum\left(\frac{1}{\operatorname{Sn} 1,2,3}\right)}
$$

\section{Results and Discussion \\ General hydrochemistry}

The concentrations of general hydrochemical variables of the Karmanasha River including minimum, maximum, mean and standard deviation and their comparison with WHO and NDWQS are presented in Table 1. The $\mathrm{pH}$ is a measure of the acidity or alkalinity of water, expressed in terms of its concentration of hydrogen ions [4,32]. It has a major role in freshwater environments for determining the speciation of inorganic chemicals and influencing the biotic life. Higher $\mathrm{pH}$ tends to precipitate the ionic species [32]. From the spatial characterization, it is found that sampling stations 1, 2 and 3 represent natural condition in the area of very few agricultural activities. Sampling stations 4 to 9 are mostly affected by agricultural, as well as brick kilns activities, whereas stations 10 to 16 are affected by almost all type of pollutants from residential, agricultural and to industrial activities (Fig. 1). The presence of industries and human influences caused the water quality poor due to pollution. In this study, the $\mathrm{pH}$ of the water was found to be slightly alkaline (ranges between 7.7 and 8.8, average 8.07) within the standard (range between 6.5 and 8.5 ) given by NDQWS thus this river water is suitable for domestic and other usages.

The EC values indicate the concentrations of TDS 
[8,33]. The EC value ranges from 227 to $512 \mu \mathrm{S} /$ $\mathrm{cm}$, with an average value of $331.69 \mu \mathrm{S} / \mathrm{cm}$ and this value is within the limit of WHO i.e., $<1500 \mu \mathrm{S} /$ $\mathrm{cm}$. Primarily the anthropogenic interference may responsible for the relatively high value of EC in river water. Simply, TDS is the measurement of all the dissolved particles, both organic and inorganic matters in water. These remains in dissolved condition from various sources such as runoff, waste water, stormflow and urban runoff, which contribute in TDS $[34,35]$. In addition, the variation in the concentrations of dissolved solids is indication of a climatic control on the intensity of processes operating in the source area $[35,36]$. The excess TDS are natural and/or anthropogenic pollutants in the water and imparts the color, total alkalinity and conducting nature of water and increases the risk for the cultivated land as well as aquatic lives. Primary causes of higher amount of TDS in the river water is possibly due to rock weathering, agricultural runoff, discharge of domestic waste from the town and other human activities. The value of TDS in the Karmanasha River varies 118$267 \mathrm{mg} / \mathrm{L}$, with an average value $172.69 \mathrm{mg} / \mathrm{L}$ and the WHO standard is $500 \mathrm{mg} / \mathrm{L}$. Optimum values of TDS in drinking water are generally not harmful to human beings but it is a serious matter of concern for those persons who are affected by cardiac and renal diseases [4,10,16,21,25,37,38].

Ionic concentrations in river water generally increases with an increasing basin area. Generally, the cationic order follow the order of $\mathrm{Ca}^{2+}>\mathrm{Mg}^{2+}>\mathrm{Na}^{+}>\mathrm{K}^{+}$. The

Table 1: General hydrochemistry of the Karmanasha River, Lalitpur, Nepal (values are expressed in $\mathrm{mg} / \mathrm{L}$ except $E C$ $(\mu \mathrm{S} / \mathrm{cm})$ and $\mathrm{pH})$

\begin{tabular}{|c|c|c|c|c|c|c|}
\hline Param. & Min & Max & Mean & SD & NDWQS & WHO \\
\hline $\mathrm{pH}$ & 7.70 & 8.80 & 8.07 & 0.36 & $6.5-8.5$ & $6.5-8.5$ \\
\hline $\mathrm{EC}$ & 227.00 & 512.00 & 331.69 & 83.22 & - & 1000 \\
\hline TDS & 118.00 & 267.00 & 172.69 & 43.72 & - & 100 \\
\hline $\mathrm{Ca}^{2+}$ & 24.00 & 46.40 & 32.35 & 4.66 & - & 50 \\
\hline $\mathrm{Mg}^{2+}$ & 5.37 & 14.64 & 10.00 & 2.93 & - & 200 \\
\hline $\mathrm{Na}^{+}$ & 1.20 & 15.00 & 6.47 & 3.91 & & 100 \\
\hline $\mathrm{K}^{+}$ & 2.40 & 4.20 & 2.50 & 0.98 & - & 250 \\
\hline $\mathrm{Cl}^{-}$ & 14.20 & 19.17 & 16.42 & 1.66 & 50 & 50 \\
\hline $\mathrm{NO}_{3}^{-}$ & 0.01 & 0.08 & 0.04 & 0.02 & 50 & 600 \\
\hline $\mathrm{HCO}_{3}^{-}$ & 110.00 & 200.00 & 142.50 & 27.87 & & 5.00 \\
\hline DO & 4.50 & 11.00 & 8.46 & 1.84 & & \\
\hline $\begin{array}{l}\text { BOD } \\
\text { COD }\end{array}$ & $\begin{array}{l}25.00 \\
75.00\end{array}$ & $\begin{array}{l}120.83 \\
362.50\end{array}$ & $\begin{array}{l}70.32 \\
210.94\end{array}$ & $\begin{array}{l}29.65 \\
88.96\end{array}$ & - & - \\
\hline
\end{tabular}

arrangement of anionic dominance based on the average value of the Karmanasha River follow the order: $\mathrm{HCO}_{3}>\mathrm{Cl}^{-}>\mathrm{NO}_{3}$. These results are consistent with the previous studies [4,14]. In addition, the mean values of DO, BOD and COD are within the desirable limits, whereas the maximum values exceed the guideline values indicating the potential anthropogenic pollution sources in the river.

\section{Suitability for irrigation quality}

Irrigation suitability of major 16 sampling points in the Karmanasha River has been evaluated using different methods and presented in Table 2. From the classification of EC suggested all the points are of "Excellent" category and concluded that the river water is acceptable for the irrigation purposes. The $\mathrm{Na} \%$ (sodium hazard) in the Karmanasha River ranges from 6.53-30.30\%, categorized as Good and Excellent for irrigation. Additionally, the SAR values of this river water $(<0.80)$ indicate the "Excellent" category also signify the potentiality of usage of this water for irrigation [4]. Similarly, the MAR value also shows that this river is suitable for irrigation. Both the MAR $(<50)$ and KR value $(<0.25)$ values belongs to the safe category. This suggests that this river water is suitable for irrigation. The value of PI was found to be $<76.54$ which means the river lies in Category I and Category II means they are good and permissible. CROSS values of the Karmanasha River are found in "Excellent" category (Table 2). The results showed good agreement with the previous studies from Nepal Himalayan Rivers $[3,4]$.

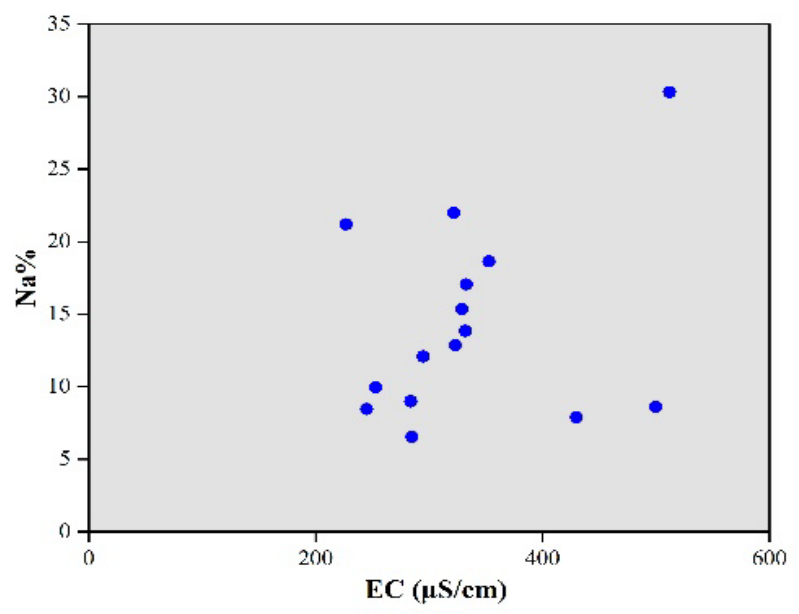

Figure 2: Classification of the Karmanasha River water based on $N a \%$ versus EC values 
Table 2: Irrigation suitability assessment of the Karmanasha River, Lalitpur Nepal

\begin{tabular}{lllllllllllllll}
\hline ID & EC & Class & SAR & Class & Na\% & Class & MH & Class & KR & Class & PI & Class & CROSS & Class \\
S1 & 227 & E & 0.67 & E & 21.19 & G & 24.3 & S & 0.24 & Safe & 73.25 & II & 0.54 & E \\
S2 & 245 & E & 0.18 & E & 8.45 & E & 21.03 & S & 0.06 & Safe & 65.32 & II & 0.17 & E \\
S3 & 253 & E & 0.22 & E & 9.97 & E & 28.33 & S & 0.08 & Safe & 73.37 & II & 0.21 & E \\
S4 & 285 & E & 0.07 & E & 6.53 & E & 33.7 & S & 0.03 & Safe & 76.54 & I & 0.11 & E \\
S5 & 284 & E & 0.2 & E & 8.96 & E & 42.07 & S & 0.07 & Safe & 59.51 & II & 0.2 & E \\
S6 & 295 & E & 0.3 & E & 12.08 & E & 30.35 & S & 0.1 & Safe & 61.92 & II & 0.28 & E \\
S7 & 284 & E & 0.23 & E & 9.00 & E & 38.85 & S & 0.07 & Safe & 60.7 & II & 0.22 & E \\
S8 & 332 & E & 0.42 & E & 13.85 & E & 37.31 & S & 0.13 & Safe & 62.8 & II & 0.37 & E \\
S9 & 322 & E & 0.8 & E & 21.98 & G & 35.76 & S & 0.25 & Safe & 67.14 & II & 0.66 & E \\
S10 & 329 & E & 0.48 & E & 15.35 & E & 45.02 & S & 0.15 & Safe & 65.13 & II & 0.42 & E \\
S11 & 323 & E & 0.42 & E & 12.85 & E & 22.97 & S & 0.12 & Safe & 56.53 & II & 0.35 & E \\
S12 & 333 & E & 0.54 & E & 17.06 & E & 30.35 & S & 0.17 & Safe & 70.22 & II & 0.45 & E \\
S13 & 353 & E & 0.61 & E & 18.63 & E & 33.7 & S & 0.2 & Safe & 71.67 & II & 0.51 & E \\
S14 & 430 & E & 0.14 & E & 7.87 & E & 32.03 & S & 0.05 & Safe & 68.54 & II & 0.16 & E \\
S15 & 500 & E & 0.18 & E & 8.61 & E & 42.66 & S & 0.05 & Safe & 65.22 & II & 0.2 & E \\
S16 & 512 & E & 0.19 & E & 30.3 & G & 39.83 & S & 0.06 & Safe & 65.29 & II & 0.7 & E \\
\hline
\end{tabular}

All values derived from (meq/l), E: Excellent, G: Good, , S:Suitable

The $\mathrm{Na} \%$ in (Figure 2) also indicates that the river has medium values as compared to other rivers in the present study. In particular, the Karmanasha River water is of good quality in terms of irrigation. High $\mathrm{Na} \%$ in river water has not been reported in any site of this River, so this indicates the river lies in good and excellent category and is suitable for irrigation purposes. The sodium or alkali hazard refers to high concentrations of sodium relative to the total cation concentrations, particularly calcium and magnesium. The higher the proportion of sodium i.e., higher the SAR values, the higher will be sodium or alkali hazard [29].

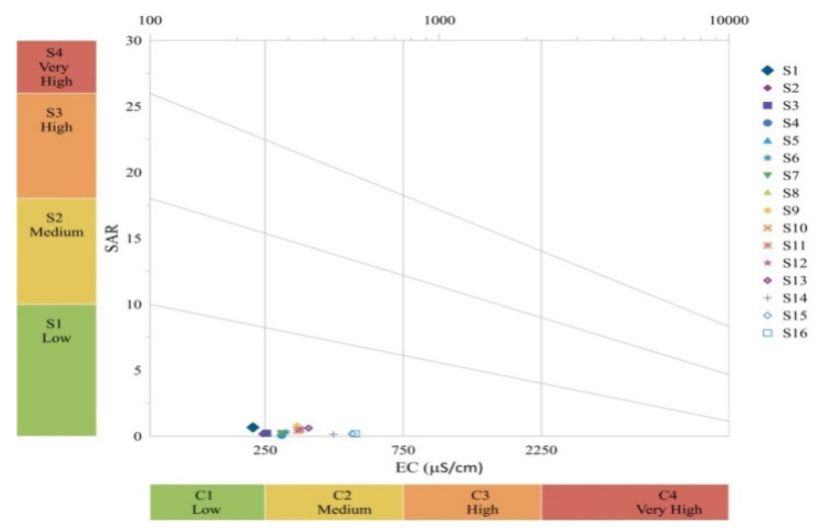

Figure 3: Wilcox diagram for classifying irrigation water on the basis of SAR and EC
Similarly, the results have also been reported with good to permissible use of water for irrigation in other Himalayan rivers such as Damodar River [39], Rangit River [40], rivers in Kumaun region [41], Ganges in Bengal [42] in India and Gandaki River in Nepal [3] based on SAR. After interpretation of Wilcox diagram (Figure 3, and Table 3), indicating major two classes: C1S1, C2S1.

Table 3: Wilcox diagram classification

\begin{tabular}{ll}
\hline Group & Wilcox Classification \\
\hline Class & Water quality for agriculture \\
C1S1 & $\begin{array}{l}\text { Sweet-completely } \\
\text { ineffective for agriculture } \\
\text { Brackish-approximate perfect } \\
\text { for agriculture }\end{array}$ \\
C1S2, C2S2, C2S1 & $\begin{array}{l}\text { Passion-usable for } \\
\text { agriculture }\end{array}$ \\
C3S3 & C2S3, C3S1, C3S \\
C4S4, C4S1, C1S4, C2S4, & $\begin{array}{l}\text { Very passion-harmful to } \\
\text { C3S4, C4S4, C4S3 }\end{array}$ \\
\hline
\end{tabular}

Source: [30]

The results in C1S1 was found (low salinity and low sodium hazard) category indicate the best quality for irrigation purpose which completely effective for agriculture. Likewise, in C2S1 (medium salinity and low sodium hazard) category is suggesting nearly perfect for agriculture. 
Table 4: WQI and corresponding water quality status with their possible usages

\begin{tabular}{llllllll}
\hline SN & Par. & $\begin{array}{l}\text { Average } \\
\text { value }(\text { Vn })\end{array}$ & Standard values $(\mathrm{Sn})$ & $\begin{array}{l}\text { Recommended } \\
\text { agencies }\end{array}$ & $\begin{array}{l}\text { Unit } \\
(\mathrm{Wn})\end{array}$ & $\begin{array}{l}\text { Quality } \\
\text { rating (qn) }\end{array}$ & qnWn \\
\hline 1 & $\mathrm{pH}$ & 8.07 & $6.5-8.5$ & NDWQS & 0.118 & 94.94 & 11.17 \\
2 & $\mathrm{EC}$ & 331.69 & 1500 & WHO & 0.003 & 110.56 & 0.37 \\
3 & $\mathrm{TDS}$ & 172.69 & 1000 & WHO & 0.002 & 34.54 & 0.07 \\
4 & $\mathrm{DO}$ & 8.33 & 5 & WHO & 0.167 & 138.9 & 23.15 \\
5 & $\mathrm{BOD}$ & 70.32 & 50 & ICMR & 0.2 & 1406.3 & 281.26 \\
6 & $\mathrm{COD}$ & 210.94 & 250 & EPR & 0.004 & 84.38 & 0.34 \\
7 & $\mathrm{Cl}-$ & 32.84 & 250 & NDWQS & 0.004 & 13.14 & 0.05 \\
8 & $\mathrm{HCO}_{3}^{-}$ & 142.5 & 600 & WHO & 0.005 & 71.25 & 0.36 \\
9 & $\mathrm{Ca}^{2+}$ & 32.35 & 100 & WHO & 0.013 & 43.13 & 0.58 \\
10 & $\mathrm{Mg}^{2+}$ & 10 & 50 & WHO & 0.02 & 20.01 & 0.4 \\
11 & $\mathrm{Na}^{+}$ & 6.47 & 200 & WHO & 0.005 & 3.23 & 0.02 \\
12 & $\mathrm{~K}^{+}$ & 2.5 & 100 & WHO & 0.003 & 3.23 & 0.02 \\
13 & $\mathrm{NO}_{3}^{-}$ & 0.04 & 50 & WHO & 0.022 & 0.08 & 0.02 \\
& & & & & & $\sum \mathrm{qnWn}=$ \\
\hline
\end{tabular}

\section{Water quality index (WQI)}

WQI of the Karmanasha River was computed from the average values of physicochemical parameters taken.

Table 5: Calculation of WQI of the Karmanasha River with an average value of each parameter

\begin{tabular}{|c|c|c|c|}
\hline S. $\mathbf{N}$. & WQI & Status & Possible uses \\
\hline 1 & $0-25$ & Excellent & $\begin{array}{l}\text { Drinking, irrigation and } \\
\text { industrial }\end{array}$ \\
\hline 2 & $26-50$ & Good & $\begin{array}{l}\text { Drinking, irrigation and } \\
\text { industrial }\end{array}$ \\
\hline 3 & $51-75$ & Fair & Irrigation and industrial \\
\hline 4 & $76-100$ & Poor & Irrigation \\
\hline 5 & $101-150$ & Very poor & $\begin{array}{l}\text { Restricted use for } \\
\text { irrigation }\end{array}$ \\
\hline 6 & $>150$ & $\begin{array}{l}\text { Unfit for } \\
\text { drinking }\end{array}$ & $\begin{array}{l}\text { Proper treatment } \\
\text { required before use }\end{array}$ \\
\hline
\end{tabular}

The calculation of the WQI on the basis of these parameters is shown in Table 4 and corresponding water quality status is also shown in Table 5.

\section{Conclusion}

This study analyzed and expressed the hydrochemical characterization and irrigation suitability of the Karmanasha River water, Lalitpur Nepal. Hydrochemistry of the Karmanasha River basically indicates slightly alkaline nature with $\mathrm{pH}$ value of 8.07. $\mathrm{HCO}_{3}^{-}$is the dominant anion and $\mathrm{Ca}^{2+}$ is the dominant cation in the sampling stations of the river. The mean EC and TDS values indicated that the river has medium salinity which directly affected by the various anthropogenic activities. The grand mean values of the major ions follow the order $\mathrm{Ca}^{2+}>\mathrm{Mg}^{2+}>\mathrm{Na}^{+}>\mathrm{K}^{+}$for cations and $\mathrm{HCO}_{3}>\mathrm{Cl}^{-}>\mathrm{NO}_{3}^{-}$ for anions. The results revealed that the water is safe for irrigation purposes based on $\mathrm{EC}, \mathrm{Na} \%$, SAR, KR, MAR, and CROSS. Wilcox diagram also revealed that the river is safe for irrigation purposes and fall on the major two categories (C1S1 and C2S1). However, the river water of the Karmanasha is not appropriate for the drinking purposes mainly due to the high values of BOD and COD. The Water Quality Index (WQI) is also indicted that the water is not fit for the drinking purposes. This study provides the baseline information about the WQI and suitability of irrigation water quality, and further studies are recommended at spatiotemporal levels for getting the in-depth insights about the ecological health of the river. 


\section{Acknowledgements}

The authors acknowledge the laboratory support provided by the Central Department of Environmental Science, Institute of Science and Technology, Kirtipur, Kathmandu, Nepal.

\section{References}

1. J. Chen, F. Wang, X. Xia, and L. Zhang, Major element chemistry of the Changjiang (Yangtze River), Chemical Geology, 2020, 187(3-4), 231-255.

2. A. N. Sharpley, W. J. Gburek, G. Folmar, and H. B. Pionke, Sources of phosphorus exported from an agricultural watershed in Pennsylvania, Agricultural Water Management, 1999, 41(2), 77-89.

3. R. J. Gibbs, Mechanisms controlling world water chemistry, Science (80), 1970, 170(3962), 1088-1090.

4. R. R. Pant, F. Zhang, F. U. Rehman, G. Wang, M. Ye, C. Zeng and H. Tang, Spatiotemporal variations of hydrogeochemistry and its controlling factors in the Gandaki River Basin, Central Himalaya Nepal, Science of the Total Environment, 2018, 622, 770-782.

5. M. Meybeck, and A. Ragu, River discharges to the oceans: An assessment of suspended solids, major ions, and nutrients, UNEP, France, 1997, 241-245.

6. A. Haidary, B. J. Amiri, J. Adamowski, N. Fohrer and K. Nakane, Assessing the impacts of four land use types on the water quality of wetlands in Japan, Water Resources Management, 2013, 27(7), 2217-2229.

7. X. Huang, M. Sillanpää, B. Duo, and E.T. Gjessing, Water quality in the Tibetan plateau: metal contents of four selected rivers, Environmental Pollution, 2008, 156(2), 270-277.

8. K. B. Pal, R. R. Pant, B. Rimal, and A. D. Mishra, Comparative assessment of water quality in the Bagmati River basin, Nepal, ZOO-Journal, 2019, 5, 68-78.

9. P. Kumari, Irrigation water quality based on hydro chemical analysis of Ganga-Sone Divide Region of Bihar, Asian Journal of Water, Environment and Pollution, 2017, 14(3), 75-83.

10. N-M. Mohammed, Quality assessment of Tigris river by using water quality index for irrigation purpose, European Journal of Scientific Research, 2011, 57(1), 15-28.

11. M. Salifu, F. Aidoo, M.S. Hayford, D. Adomako and E. Asare, Evaluating the suitability of groundwater for irrigational purposes in some selected districts of the Upper West region of Ghana, Applied Water Science, 2017, 7(2), 653-662.
12. L. Yang, G. Zhu, P. Shi, J. Li, Y. Liu, H. Tong, P. Hu, F. Liang, H. Pan, H. Guo and Y. Zhang, Spatiotemporal characteristics of hydrochemistry in Asian arid inland basin-a case study of Shiyang River basin, Environmental Science and pollution Research, 2018, 25(3), 2293-2302.

13. C. M. Sharma, S. Kang, L. Tripathee, Major ions and irrigation water quality assessment of the Nepalese Himalayan rivers, Environment Development and Sustainability, 2020, 1-13. (DOI:10.1007/s10668-020-00694-1).

14. K. I. Zheng, F. Gao, X. Wang, Q. Sun, K. Pan, T. Wang, H. Ma, W. Liu and M. Zheng, Journal of Metabolism, 2020, 154244.

15. R. R. Pant, F. Zhang, F. U. Rehman, M. Koirala, K. Rijal, and R. Maskey, Spatiotemporal characterization of dissolved trace elements in the Gandaki River, Central Himalaya Nepal, Journal of Hazardous Materials, 2019; 389, 121913. (https://doi.org/10.1016/j.jhazmat.2019.121913).

16. R. R. Pant, Water quality assessment of Nagdaha lake, Lalitpur, Nepal, Journal of Tribhuvan University Campus Unit, 2013, 8, 52-56.

17. S. H. Jenkins, Standard methods for the examination of water and wastewater, Water Environment Federation, 1982, 16(10), 1495-1496.

18. A-H-M-J Alobaidy, M. A. Al-Sameraiy, A. J. Kadhem, and A. A. Majeed, Evaluation of treated municipal wastewater quality for irrigation, Journal of Environmental Protection, (Irvine,. Calif), 2010, 01(03), 216-225.

19. P. Debels, R. Figueroa, R. Urrutia, R. Barra and X. Niell, Evaluation of water quality in the Chillán River (Central Chile) using physicochemical parameters and a modified Water Quality Index, Environmental Monitoring and Assessment, 2005, 110(1-3), 301-322.

20. G. Fipps, Standards and salinity management water analysis, Agrilife Exttension, 1995, 4(3),1-17.

21. R. S. Ayers, and D. W. Westcot, Water Quality for Agriculture, 1985, 29.

22. L. D. Doneen, Salination of soil by salts in the irrigation water, Transactions American Geophysical Union, 1954, 35, 3-7.

23. D. M. Joshi, A. Kumar, and N. Agrawal, Assessment of the irrigation water quality of river Ganga in Haridwar district, Rasayan Journal of Chemistry, 2009, 2(2), 285-292.

24. N. R Subba, Seasonal variation of groundwater quality in a part of Guntur District, Andhra Pradesh, India, Environmental Geology, 2006, 49(3), 413-429. 
25. L. A. Richards, Diagnostics and improvement of saline and alkaline soils, U.S. Dept. Agric. hand B. no. 60, U.S. Salin. Lab, Washington, DC, 1954.

26. M. Al-Shammiri, A. Al-Saffar, S. Bohamad, and M. Ahmed, Waste water quality and reuse in irrigation in Kuwait using microfiltration technology in treatment, Desalination, 2005, 185(1-3), 213-225.

27. W. P. kelley, Use of saline irrigation water, Soil Science, 1963, 95(4), 355-391.

28. P. Rengasamy, A. Marchuk, Cation ratio of soil structural stability (CROSS), Soil Research, 2011, 49(3), 280-285.

29. L. V. Wilcox, The quality of water for irrigation use, Technical Bulletin, US, Department of Agriculture, 1948, 962-981.

30. N. Alavi, E. Zaree, M. Hassani, A. A. Babaei, G. Goudarzi, A. R. Yari and M. J. Mohammadi, Water quality assessment and zoning analysis of Dez eastern aquifer by Schuler and Wilcox diagrams and GIS, Desalination and Water Treatment, 2016, 57(50), 23686-23697.

31. A. Magadum, T. Patel, and D. Gavali, Assessment of physicochemical parameters and water quality index of Vishwamitri River, Gujarat, India, International Journal of Environment, Agriculture and Biotechnology, 2017, 2(4), 1505-1510.

32. R. R. Maurya, Determination of physicochemical parameters and water quality index (Wqi) of Chandlodia Lake, Ahmedabad, Gujarat, India, Journal of Environmental and Analytical Toxicology, 2015, 5(288), 2161-0525. (DOI:10.4172/2161-0525.1000288).

33. S. P. Kayastha, Geochemical parameters of water quality of Karra River, Hetauda Industrial Area, Central Nepal, Journal of Institute of Science and Technology, 2015, 20(2), 31-36.

34. R. R. Pant, F. Zhang, F. R. Qaiser, and R. Maskey, Contrasting characteristics of water quality in Kali and Seti Rivers, Central Himalaya, Gandaki Province - Nepal. Int. Lake Conf. Sustain. Util. Lake Resour. Pokhara, 2018, Kathmandu, National Lake Conservation Development Community (NLCDC), 2018, 7, 121-129.

35. R. R. Pant, T. M. Dhakal, L. B. Thapa, U. Baral, A. Dangol, T. B. Chalaune, and K. B. Pal, Water quality assessment of the Betkot lake, Sudurpaschim Province, Nepal, North American Academic Research, 2019. (https://doi.org/https:// doi.org/10.5281/zenodo.3566682).

36. A. K. Singh, S. I. Hasnain, Chimie des éléments majeurs et érosion dans un bassin de haute montagne (Alaknanda, Garhwal Himalaya, Inde), Hydrological Sciences Journal, 1998, 43(6), 825-843.

37. A. F. Rusydi, Correlation between conductivity and total dissolved solid in various type of water: A review, In IOP Conference Series: Earth and Environmental Science, 2018, 118(1). (DOI:10.1088/1755-1315/118/1/012019).

38. A. B. Gebrehiwot, N. Tadesse, and E. Jigar, Application of water quality index to assess suitablity of groundwater quality for drinking purposes in Hantebet watershed, Tigray, Northern Ethiopia, ISABB, Journal of Food and Agricultural Sciences, 2011, 1(1), 22-30.

39. A. K. Singh, G. C. Mondal, S. Kumar, T. B. Singh, B. K. Tewary and A. Sinha, Major ion chemistry, weathering processes and water quality assessment in upper catchment of Damodar River basin, India. Environmental Geology, 2008, 54(4), 745-758.

40. S. Gupta, S. Nayek, and D. Chakraborty, Hydrochemical evaluation of Rangit river, Sikkim, India: using water quality index and multivariate statistics, Environmental Earth Science, 2016. (DOI:10.1007/s12665-015-5223-8).

41. R. Seth, M. Mohan, P. Singh, R. Singh, R. Dobhal, K. P. Singh and S. Gupta, Water quality evaluation of Himalayan Rivers of Kumaun region, Uttarakhand, India, Applied Water Science, 2016, 6(2), 137-147.

42. S. K. Mandal, S. K. Dutta, S. Pramanik, and R. K. Kole, Assessment of river water quality for agricultural irrigation, International Journal of Environmental Science and Technology, 2019, 16(1), 451-462.

43. R. R. Pant, K. B. Pal, N. L. Adhikari, S. Adhikari, and A. D. Mishra, Water quality assessment of Begnas and Rupa lakes, Lesser Himalaya Pokhara, Nepal, Journal of Institute of Engineering, 2019, 15, 113-122.

44. S. K. Pathak, S. Prasad, and T. Pathak, Determination of water quality index River Bhagirathi in Uttarkashi, Uttarakhand, India, International Journal of Research Granthalayah, 2015, 3(9), 1-7.

45. R. R. Pant, N. L. Adhikari, Water quality assessment of Phewa lake, Pokhara, Nepal, Cognitive Transdisciplinary, Research Journal, 2015, 1, 130-140.

46. X. Sun, Q. Zhang, M. Li, K. Kandel, B. Rawat, A. Pandey, J. Guo, S. Kang, R. R. Pant, Z. Cong, and F. Zhang, Mercury variation and export in trans-Himalayan rivers: Insights from field observations in the Koshi River, Science of the Total Environment, 2020, 738, 139836. 